\title{
Architects at the bacterial surface - sortases and the assembly of pili with isopeptide bonds
}

Antoni P. A. HendrickX, Jonathan M. Budzik, So-Young Oh and Olaf Schneewind

Abstract | The cell wall envelope of Gram-positive bacteria can be thought of as a surface organelle for the assembly of macromolecular structures that enable the unique lifestyle of each microorganism. Sortases - enzymes that cleave the sorting signals of secreted proteins to form isopeptide (amide) bonds between the secreted proteins and peptidoglycan or polypeptides - function as the principal architects of the bacterial surface. Acting alone or with other sortase enzymes, sortase construction leads to the anchoring of surface proteins at specific sites in the envelope or to the assembly of pili, which are fibrous structures formed from many protein subunits. The catalysis of intermolecular isopeptide bonds between pilin subunits is intertwined with the assembly of intramolecular isopeptide bonds within pilin subunits. Together, these isopeptide bonds endow these sortase products with adhesive properties and resistance to host proteases.

Electron microscopy was essential for the study of microbial surfaces, as only this technology could reveal the intricate structures of cell wall peptidoglycan, S-layers (crystalline surface layers), pili and surface proteins ${ }^{1-4}$. Pili in Gram-positive bacteria were first detected in 1968, when Yanagawa and colleagues ${ }^{5,6}$ reported fibrous structures on the surface of Corynebacterium renale and Corynebacterium diphtheriae. The discovery that sortase enzymes are responsible for the surface display and cell wall anchoring of surface proteins carrying the sortase recognition motif LPXTG, and that these enzymes catalyse pilus polymerization, was an important insight into the cell biology of Gram-positive bacteria ${ }^{7-9}$. Sortases are transpeptidase enzymes that covalently connect their substrates to a target molecule ${ }^{7,10-12}$. Structures of multiple sortases from different bacteria have been solved and display comparable overall compositions ${ }^{13-21}$; the backbone is similar among isoforms and consists of an uneven eight-stranded $\beta$-barrel with connecting random-coil loops. All sortases contain a TLXTC motif in their active site as well as multiple conserved residues that are required for transpeptidation activity.

Genome sequencing of Gram-positive bacteria has uncovered thousands of genes encoding proteins with LPXTG sorting signals, alongside a plethora of sortase genes $^{22-24}$, suggesting that these enzymes cannot all act on the same substrates ${ }^{25,26}$. Therefore, sortases have been classified into four groups (sortase classes A-D) on the basis of sequence homology, the substrate for sortase cleavage and the nucleophile accepted by the sortase ${ }^{27}$ (TABLE 1). Note that the sortase class A-D classification is used throughout this manuscript. However, many sortases have received designations that relate to the order of their discovery in various Gram-positive bacteria; to avoid confusion, these enzymes are described with the acronyms SrtA-F.

Sortase class A enzymes are present in all Grampositive bacteria and are often referred to as housekeeping sortases. They recognize the sequence LPXTG at the carboxyl terminus of surface protein precursors ${ }^{7,9-11,28}$. The product of the sortase class A reaction is a surface protein that is covalently linked to lipid II and is then incorporated into the cell wall envelope (FIG. 1). Sortase class A substrates include surface proteins from the microbial surface components recognizing adhesive matrix molecules (MSCRAMM) family that have been implicated in the virulence of multiple Gram-positive bacterial species ${ }^{22,29,30}$.

Sortase class B enzymes are encoded by several Staphylococcus spp., Bacillus spp., Listeria spp. and Clostridium spp. ${ }^{17,31-34}$. Sortase class B enzymes recognize a unique $\mathrm{NP}(\mathrm{Q} / \mathrm{K}) \mathrm{TN}$ sorting signal in proteins that are involved in haem-iron scavenging, and cross-link the anchored haem-containing products near membrane 
Table 1 | Sortase classes, substrate specificity and nucleophiles

\begin{tabular}{llll} 
Sortase class & Substrates & Substrate motif & Nucleophile \\
\hline A & Surface proteins & LPXTG & Lipid II ${ }^{9,28,10}$ \\
\hline B & Haem transport factor & NP(Q/K)TN & Peptidoglycan crossbridge ${ }^{33,34}$ \\
C & Pilin proteins & $(\mathrm{I} / \mathrm{L})(\mathrm{P} / \mathrm{A})$ XTG & Lys residue of pilins $^{27,35}$ \\
\hline D & Mother cell and endospore envelope proteins & LPNTA & Lipid II $^{37,38}$ \\
\hline
\end{tabular}

transporters. The $\beta$-barrel structure of sortase class $\mathrm{B}$ enzymes is similar to that of the class A enzymes but encompasses additional $\alpha$-helices ${ }^{17,18}$.

The pilin-specific class $\mathrm{C}$ sortases polymerize pili by catalysing transpeptidation reactions that form covalent links between individual subunits of these fibrous structures $^{35}$. In contrast to sortases that only accept single cell wall peptides as nucleophiles, pilin-specific sortases recognize multiple pilin proteins both as substrates for cleavage of the LPXTG-like motif and as nucleophiles. Pilin-specific class $\mathrm{C}$ sortases are encoded in pilin gene clusters with their cognate substrates and often contain a C-terminal hydrophobic domain not found in sortases from other classes. The crystal structures of the three pilin-specific sortase class C enzymes from Streptococcus pneumoniae ( $\mathrm{SrtB}, \mathrm{SrtC}$ and $\mathrm{SrtD}$ (also known as SrtC1, SrtC2 and SrtC3, respectively)) revealed that these enzymes adopt structures comparable to those of sortase class A and sortase class B proteins ${ }^{14,15}$. Interestingly, the $\alpha 3$ helix forms a flexible lid over the active site; this is a unique feature of pilin-specific sortases and is required for efficient polymerization of pili and for enzyme stability ${ }^{36}$.

Last, sortase class D enzymes are expressed in spore-forming microorganisms. In Bacillus spp. and Streptomyces spp., sortase class D enzymes recognize and cleave the sorting signals of select substrates to immobilize their anchored products in the cell wall envelope during spore formation ${ }^{37,38}$. To date, no crystal structure of a sortase class D enzyme has been solved.

Here, we review mechanisms of sortase action and the role of sortases in the formation of pili, as well as the development of vaccines to prevent infections by Gram-positive bacteria.

\section{Mechanism of cleavage}

All sortases recognize a specific sorting signal at the C terminus of their target protein. The specificity of cleavage is determined by recognition of sortasespecific sorting signals (TABLE 1); each sortase cleaves its specific sorting signal and subsequently forms an acyl (thioester) bond between the sortase active site and a residue in the sorting signal. This acyl intermediate is then resolved by a specific nucleophilic amino acid, thus specifying the cell wall component to which the protein becomes linked. For example, in Staphylococcus aureus the class A sortase cleaves the LPXTG sorting signal between the Thr and Gly residues to form an acyl intermediate between the Thr residue of the surface protein and a reactive Cys in the TLXTC catalytic pocket of the sortase (FIG. 1). Subsequently, the acyl intermediate is resolved by nucleophilic attack by the cell wall precursor lipid II. In S. aureus, lipid II consists of an undecaprenylpyrophosphate anchor linked to $\mathrm{N}$-acetylmuramyl (MurNAc), which is in turn bound to $\mathrm{N}$-acetylglucosamine (GlcNAc) and to the cell wall pentapeptide L-Ala- $\gamma$-D-Gln-L-Lys-D-Ala-D-Ala; the L-Lys is bound to a short peptide (a pentaglycine in $S$. aureus) that will normally form the crossbridge between two pentapeptides of different peptidoglycan strands ${ }^{28}$. However, the terminal amino acid of the pentaglycine can also 'attack' the linkage between the sortase and the surface protein, forming an amide bond that tethers the surface protein to lipid II in the bacterial plasma membrane. Subsequent steps then transfer the polysaccharide residues and the attached protein to the peptidoglycan cell wall. In order to solubilize sortaseanchored proteins, murein (peptidoglycan) must therefore be treated with peptidoglycan hydrolases ${ }^{39,40}$.

$\mathrm{SrtD}$, the pilin-specific class C sortase of Bacillus cereus, cleaves the $(\mathrm{I} / \mathrm{L})(\mathrm{P} / \mathrm{A}) \mathrm{XTG}$ sorting signal of pilin precursors ${ }^{41}$. The acyl intermediate between SrtD and pilins is resolved by nucleophilic attack by the side chain $\varepsilon$-amino group of Lys from within another pilin subunit. The result of this reaction is two covalently linked surface proteins, which can be extended by further polymerization into a pilus structure. Similarly to cell wall-anchored surface proteins, the polymerized pilin subunits are immobilized within the murein sacculus (the peptidoglycan cell wall) by the housekeeping class A sortase $\mathrm{e}^{8,42-44}$.

\section{Linking protein secretion to cell wall synthesis}

Protein secretion and cell wall sorting of surface proteins by sortases appear to be coordinated with sites of cell wall synthesis, as polypeptides can be linked to lipid II. Penicillin-binding proteins assemble the bacterial murein sacculus using lipid II as a substrate for transglycosylation and transpeptidation reaction $\mathrm{s}^{45,46}$. These enzymes first polymerize the glycan strands (MurNAcGlcNAc-MurNAc-GlcNAc) and subsequently catalyse cross links between the amino groups of the crossbridges and the carboxyl groups of $\mathrm{D}$-Ala residues at position four in the cell wall pentapeptides ${ }^{47,48}$. The subcellular location of cell wall synthesis varies between bacterial species. In Gram-positive cocci, including staphylococci and streptococci, bulk cell wall synthesis occurs at the site of cell division ${ }^{49}$, whereas rod-shaped bacilli and listeriae catalyse de novo peptidoglycan synthesis mostly in helical arrangements along the cylindrical cell ${ }^{50}$. Within a fully assembled cell wall, crossbridges cross-link neighbouring wall peptides ${ }^{51}$.

Because of the link between cell wall synthesis and anchoring of proteins to the cell wall by sortases, it seems plausible that there are assembly sites at which protein secretion and cell wall synthesis machines can 


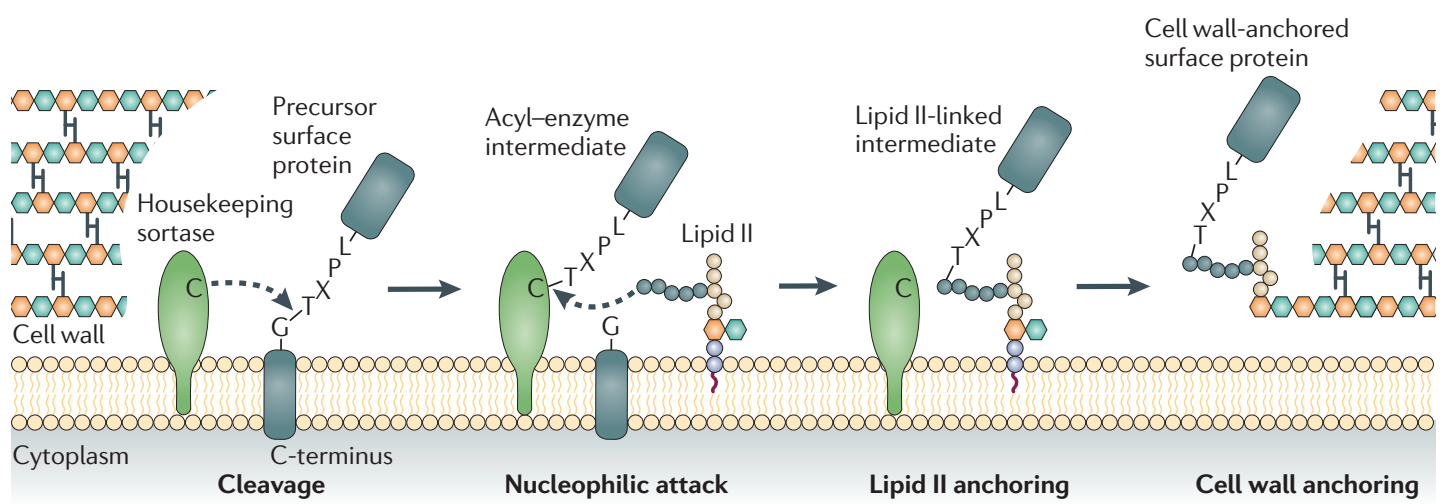

Figure 1 | Mechanism of sortase-mediated surface protein anchoring to the cell wall. Surface proteins are synthesized in the cytoplasm as precursor proteins with an amino-terminal signal sequence and a carboxy-terminal sorting signal. The $\mathrm{C}$-terminal sorting signal consists of a positively charged tail, a hydrophobic region and a LPXTG motif. Following secretion by the Sec secretion system, signal peptidases cleave the signal peptides of surface proteins, thereby producing the precursor surface proteins. The active-site Cys of the sortase cleaves the amide bond between Thr and Gly of the C-terminal pentapeptide LPXTG motif and generates an acyl-enzyme (thioester) intermediate. Nucleophilic attack by the amino group within the pentaglycine crossbridge of lipid II links the C-terminal Thr of the surface protein to lipid II. Penicillin-binding proteins incorporate the precursor into the cell wall as a mature cell wall-anchored surface protein for surface display by catalyzing a transpeptidation reaction.

interact with sortases. These sites would ensure rapid incorporation of surface proteins into the bacterial envelope. Although such assemblies have thus far not been characterized, the localization of pili and the pilinspecific class $\mathrm{C}$ sortases at discrete sites near cross walls (the cell walls that separate enterococcal cells) has been reported in Enterococcus faecalis ${ }^{52}$. Future work will need to unravel whether these sites include an aggregation of protein secretion and cell wall synthesis machinery.

\section{Sortase substrate specificity and pilus design}

Polymerization of pili in Gram-positive bacteria requires cross-linking of the pilin subunits by sortases. This process is initiated through the formation of sortase class C-acyl intermediates with minor or major pilin subunits. For example, the initial step in the assembly of the $B$. cereus pilus is cleavage of the sorting signal of the pilus minor subunit, BcpB, by $\mathrm{SrtD}^{41}$ (FIG. 2a). The resulting acyl intermediate can only be resolved by nucleophilic attack by the major subunit, BcpA, ensuring that $\mathrm{BcpB}$ caps the pilus tip. Subsequent nucleophilic attacks by $\mathrm{BcpA}-\mathrm{SrtD}$ at $\mathrm{BcpB}-\mathrm{BcpA} \mathrm{A}_{n}$ SrtD intermediates promote elongation of the pilus fibre $\left(\mathrm{BcpB}-\mathrm{BcpA}_{n+1}-\mathrm{SrtD}\right)^{35}$. Unlike $\mathrm{BcpB}$, the sorting signal of which can only be cleaved by $\mathrm{SrtD}$, the sorting signal of $\mathrm{BcpA}$ is a substrate for both $\mathrm{SrtD}$ and the B. cereus housekeeping sortase, SrtA. Pilus assembly is terminated when SrtA cleaves $\mathrm{BcpA}$ at its sorting signal so that BcpA-SrtA can serve as the nucleophile acceptor for the elongated pilus ${ }^{53}$. The acyl intermediate of this reaction, $\mathrm{BcpB}-\mathrm{BcpA}_{n}-\mathrm{SrtA}$, can only be relieved by lipid II, thus the final product can be incorporated into the cell wall envelope.

A similar paradigm applies for the assembly of pili that contain three different pilin subunits (FIG. 2b). For example, the synthesis of one type of pilus in C. diphtheriae involves a minor subunit, $\mathrm{SpaC}$, that forms the adhesive tip ${ }^{8,54}$. SpaC is cleaved by the pilin-specific class
C sortase (SrtA in C. diphtheriae) ${ }^{55,56}$. The SpaC-SrtA intermediate is only relieved via nucleophilic attack by the major pilin SpaA. SpaC-SpaA - SrtA intermediates are relieved in turn by SpaA-SrtA or by SpaB-SrtF, as SpaB, one of the minor pilin subunits, also harbours a Lys $\varepsilon$-amino group nucleophile for SpaC-SpaA $-\mathrm{SrtA}^{57}$. Work on a different pilus of $C$. diphtheriae revealed that the level in that pilus of the major pilin subunit, $\mathrm{SpaH}$, determines pilus length ${ }^{58}$. The SpaB sorting signals can only be cleaved by the housekeeping class A sortase ( $\mathrm{SrtF}$ in C. diphtheriae), and then the pilus is transferred to lipid $\mathrm{II}^{59}$. In agreement with this model, $C$. diphtheriae spaB-null mutants form SpaC-SpaA ${ }_{n}$ pili but cannot immobilize these pili in the cell wall envelope $\mathrm{e}^{57}$.

\section{Structure of recombinant pilin subunits}

In 2007, the first crystal structure of a pilin protein from a Gram-positive bacterium was reported: that of Gbs52, a minor pilin that mediates attachment of pili to the cell wall envelope in Streptococcus agalactiae (group B Streptococcus; GBS) ${ }^{60}$. The recombinant pilin folds into two adjacent immunoglobulin (Ig)-like domains with seven anti parallel $\beta$-strands (FIG. 3). The C-terminal Ig-like domain is stabilized by an isopeptide bond that is autocatalytically formed between a Lys and an Asn side chain $^{61}$. A similar domain arrangement had been previously observed for the B domain of $S$. aureus collagen adhesin $(\mathrm{Cna})^{62}$, a surface protein that is linked to the cell wall by a class A sortase. These Ig-like folds containing an intramolecular isopeptide bond are called Cna-B domains. In addition to two Cna-B domains stacked on top of one another, Gbs52 carries an extended Prorich linker in close proximity to its $\mathrm{C}$-terminal sorting signal $^{61}$. This feature is conserved among minor pilin proteins that function as cell wall-anchoring subunits for those pili that are assembled from three different subunits in Gram-positive bacteria ${ }^{63}$. 

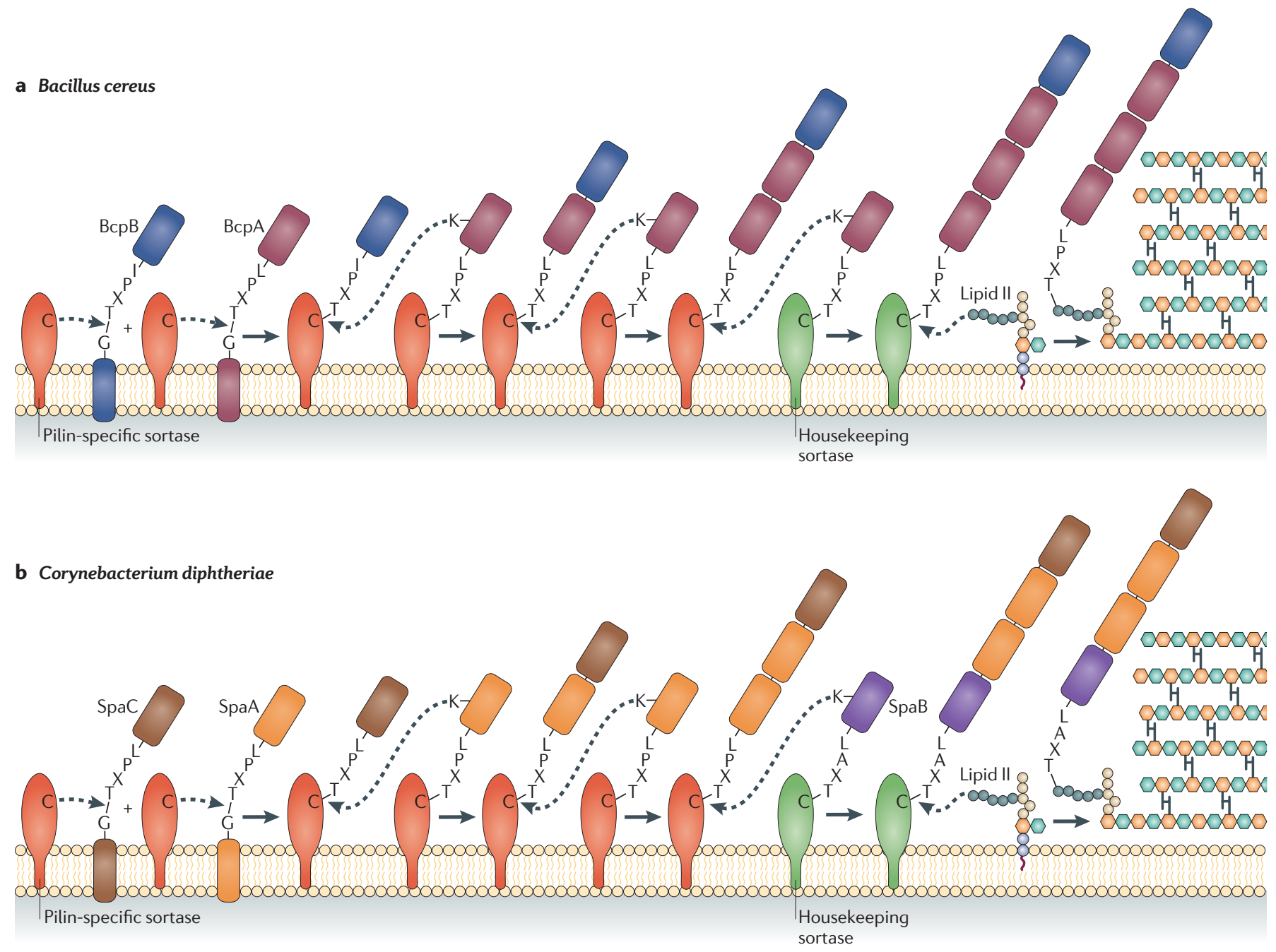

Figure 2 | Assembly mechanisms for heterodimeric and heterotrimeric pili. a | The pilin-specific sortase cleaves the sorting signals of BcpA and BcpB of Bacillus cereus at the Thr of the LPXTG motif, generating an acyl-enzyme intermediate. Nucleophilic attack by the side chain of Lys in the YPKN motif of BcpA forms an intermolecular isopeptide bond between $\mathrm{BcpB}$ and $\mathrm{BcpA}$ or $\mathrm{BcpA}$ and $\mathrm{BcpA}$, and catalyses pilus polymerization. Nucleophilic attack of lipid II on the acyl intermediate formed by the housekeeping sortase and BcpA transfers the pilus to the cell wall envelope and terminates pilus assembly. b | A similar mechanism occurs with SpaCAB pili of Corynebacterium diphtheriae. An internal isopeptide bond is formed between $\mathrm{SpaC}$ and SpaA and subsequently between the SpaC-SpaA dimer and additional SpaA subunits to allow pilus polymerization. The pilus is anchored to the cell wall via a SpaB subunit, which is already linked to the housekeeping sortase. Nucleophilic attack by Lys139 of SpaB incorporates this minor subunit into the pilus. Nucleophilic attack of lipid II at the acyl intermediate of the housekeeping sortase with SpaB transfers the pilus to the cell wall envelope and terminates pilus assembly.

Since the first description of the structure of Gbs52, several reports have described crystal structures of other recombinant pilin proteins. The major pilin subunit of the M1-type Streptococcus pyogenes (group A Streptococcus; GAS) str. SF370 pilus backbone structural protein (BP; encoded by the Spy0128 locus) ${ }^{64}$, comprises two domains with irregular all- $\beta$ structures that also represent variants of the Ig-like fold (the Cna-B domain) (FIG. 3a). In the assembled pilus, the elongated subunits are thought to be stacked head to tail, which would juxtapose the two residues involved in the intermolecular isopeptide bond, the C-terminal Thr311 of the cleaved sorting signal and the nucleophile Lys161 used in the transpeptidation reaction. BP contains two intramolecular isopeptide bonds, one per Ig-like domain ${ }^{64}$, which contribute to protease resistance and the overall stability of folded pilin subunits ${ }^{64,65}$. Both of these bonds have been identified within assembled pili, but it remains unclear whether they are formed before or after the sortasemediated assembly of the intermolecular isopeptide bond (Thr311-Lys161).

The minor pilin subunit $\mathrm{Cpa}$ (also known as ancillary protein 1; encoded by the Spy0125 locus) is located at the tip of M1-type pili in S. pyogenes str. SF370. This pilus is formed via the polymerization of $\mathrm{BP}^{44}$ and mediates streptococcal adherence to host cells (BOX 1; TABLE 2) )6,67. $^{6.67}$. 
a

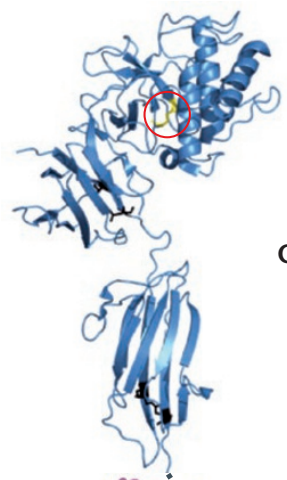

$\mathrm{Cpa}_{n=1}{ }_{n=1}$

$\mathbf{B P}_{n=x}$

FctB $_{n=1}$ b
BcpA*
SpaA
$\operatorname{Rrg} B^{*}$
Bacillus cereus
Corynebacterium diphtheriae
Streptococcus pneumoniae
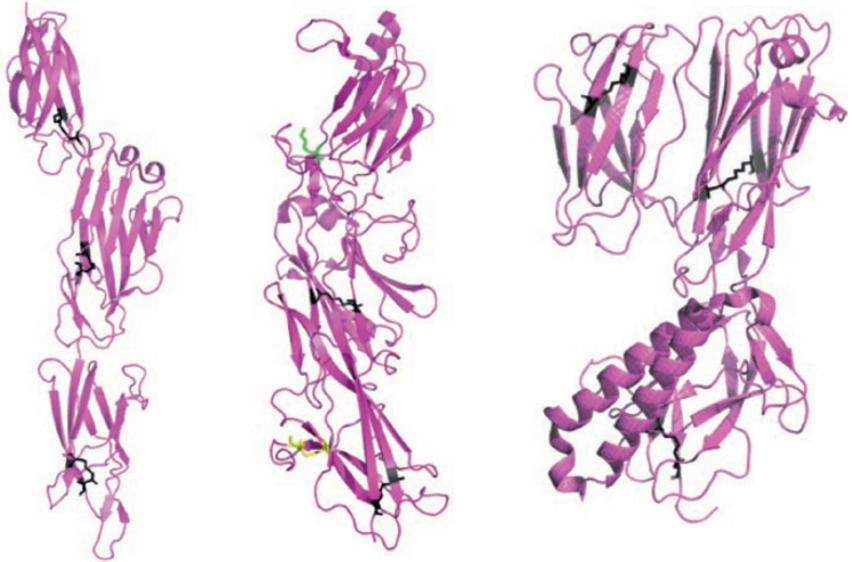

c

Gbs52

Streptococcus agalactiae

$\operatorname{RrgA}$

Streptococcus pneumoniae
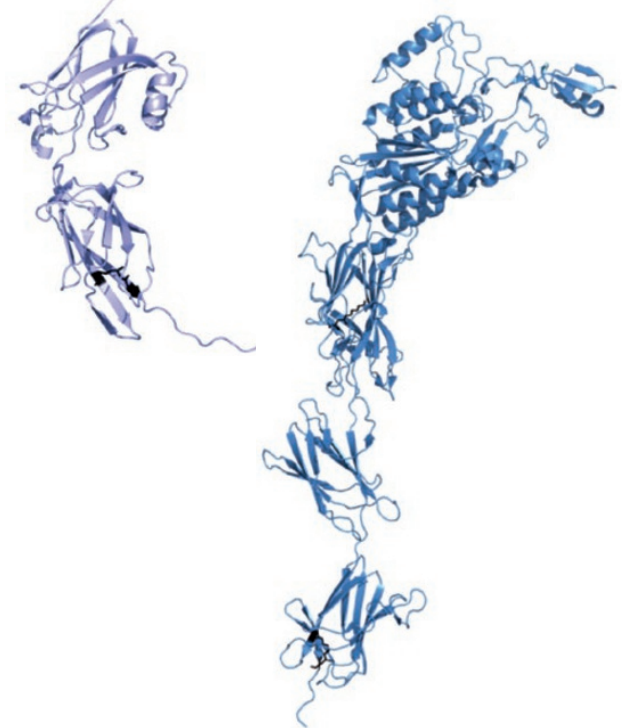

1000000000000000000000000000000000000

Cytoplasm

Figure $3 \mid$ X-ray crystal structures of Streptococcus pyogenes pilins and pilin subunits from other Gram-positive bacteria. a | Structural model of the Streptococcus pyogenes pilus formed by Cpa-BP-FctB (Cpa is also known as ancillary protein 1 and is encoded by the Spy0125 locus; backbone structural protein (BP) is encoded by the locus Spy0128; and FctB is also known as ancillary protein 2 and is encoded by the Spy0130 locus), showing that intermolecular isopeptide bonds (dashed lines) assemble the pilus, which is covalently connected to the cell wall. The tip pilin (Cpa) contains a thioester linkage (yellow, circle), in addition to intramolecular isopeptide bonds (black). b,c | Major pilin subunits (part b) and minor pilin subunits (part $\mathbf{c}$ ) are composed of variants of $C$ na-B immunoglobulin-like folds that typically contain intramolecular isopeptide bonds (black); however, SpaA also contains a disulphide bond (yellow). The Lys implicated in intermolecular amide bond formation is depicted in stick mode in green and faces outward from the structure. Asterisks indicate crystal structures of truncated recombinant proteins.

The C-terminal domain of Cpa, residues 286-723, mediates its adhesive properties and contains three domains: the middle domain (residues 291-372 and 590-597), the top domain (residues 390-583) and the bottom domain (residues 603-719) ${ }^{68}$. Of these, the middle domain and the bottom domain each adopt an Ig-like all- $\beta$ fold with an intramolecular isopeptide bond involving residues Lys297 and Asp595 in the middle domain and residues Lys610 and Asn715 in the bottom domain, similar to those found in other pilins. Remarkably, in contrast to most of these domains, which have a Lys-Asn isopeptide bond, the isopeptide bond of the Cpa 


\section{Box 1 | The function of pili in Gram-positive bacteria}

Pili are involved in adherence to host epithelial tissues, an important first step in colonization, biofilm formation and subsequent initiation of the infection processes of Streptococcus pyogenes, Streptococcus agalactiae, Streptococcus pneumoniae and Corynebacterium diphtheriae. S. pneumoniae pili adhere to lung epithelial cells and are implicated in pneumococcal colonization of the host respiratory tract ${ }^{87,96}$. Piliated S. pneumoniae strains appear to be more virulent than non-piliated strains in an invasive disease model in mice ${ }^{87}$. S. pyogenes pili bind to human tonsil epithelial cells, primary human keratinocytes ${ }^{97}$ and pharyngeal cells ${ }^{67}$, whereas the minor pilin subunits of $C$. diphtheriae, $\mathrm{SpaB}$ and $\mathrm{SpaC}$, are important for adhesion to pharyngeal epithelial cells ${ }^{54}$. S. agalactiae pili are involved in adhesion to and invasion into brain microvascular endothelial cells ${ }^{98}$ and are important for adherence to respiratory epithelial cells ${ }^{99}$. Furthermore, S. agalactiae variants lacking the major pilin subunit were less virulent than the wild-type parent in a mouse bacteraemia mode $l^{100}$. Interestingly, pili encoded by pilus islets 1 (PI-1) and PI-2a gene clusters of S. agalactiae are involved in epithelial translocation ${ }^{101,102}$, an invasive mechanism that contributes to the dissemination of S. agalactiae through host tissues. The pili of S. pyogenes and S. agalactiae contribute to biofilm formation ${ }^{67,99}$, whereas the Ebp pili of Enterococcus faecalis are involved in adherence to host cells and in biofilm formation ${ }^{85}$ and are very similar to the Ebp (PilB) pilus proteins from pilin gene cluster 3 of Enterococcus faecium ${ }^{86}$. These pili of E. faecium are implicated in enterococcal primary attachment and biofilm formation ${ }^{103}$. Competitive index analysis of mouse urinary tract infections showed that wild-type piliated E. faecalis or E. faecium outcompete non-piliated variants ${ }^{91,103,104}$. Similar results were obtained when comparing piliated and non-piliated $E$. faecalis strains in a rat endocarditis model ${ }^{85}$.

Pilin proteins of pathogenic streptococci exhibit sequence similarities to microbial surface components recognizing adhesive matrix molecules (MSCRAMMs), a class of LPXTG-containing surface proteins that are found in Gram-positive bacteria and interact with components of the extracellular matrix ${ }^{105}$ (TABLE 2). In agreement with this finding, the pilus tip proteins RrgA of S. pneumoniae and Acb of Streptococcus gallolyticus showed concentration-dependent binding to specific extracellular matrix molecules ${ }^{29,106}$. S. pyogenes pili are encoded in the fibronectinbinding, collagen-binding T antigen (FCT) region ${ }^{107}$. The FCT region of some streptococci encodes the collagen type I-binding minor pilin protein Cpa (also known as ancillary protein 1; encoded by the Spy0125 locus), which is deposited at the tip of pili, and the fibronectin-binding proteins PrtF2 and $\mathrm{PrtF}^{107-109}$. middle domain is formed between a Lys and an Asp. The top domain of Cpa harbours an internal thioester bond between Cys426 and Gln575; this type of thioester bond has also been observed in mammalian complement components and complement-like proteins that contribute to insect innate immune functions by linking to microbial elements ${ }^{69,70}$. Although the presence of the thioester bond is a compelling argument for a model whereby streptococcal pili may also form covalent links with their host cell receptors, direct proof for this conjecture is still missing.

FctB (also known as ancillary protein 2; encoded by the Spy0130 locus) is thought to be located at the base of the pilus and is required for the incorporation of the assembled fibre into the cell wall envelope ${ }^{63}$. The crystal structure of FctB of S. pyogenes str. 90/306S revealed an Ig-like fold within the $\mathrm{N}$-terminal domain and a C-terminal helix similar to a polyproline II helix (PP-II $)^{63,71}$. Recombinant FctB does not contain the intramolecular isopeptide bond that is seen in BP and Cpa; instead, a hydrogen bond network at the hydrophobic core of FctB may form a functional replacement for the stabilizing force exerted by intramolecular isopeptide bonds in other pilin domains. The N-terminal Ig-like domain contains a region referred to as the
$\Omega$-loop, which is not present in the Cna-B domain of staphylococcal $\mathrm{Cna}^{63}$. This loop contains a Lys residue that is conserved among members of the FctB family of streptococcal ancillary pilin subunits ${ }^{63}$. A similarly positioned residue, Lys161, in the $\Omega$-loop of the major pilin $\mathrm{BP}$ serves as the nucleophile in sortase-mediated assembly of these pili ${ }^{61}$. A covalent link between the Lys120 of FctB forms an intermolecular amide with the C-terminal Thr311 of $\mathrm{BP}^{63}$. The C-terminal PP-II helix appears to be a conserved feature of other minor pilin proteins ${ }^{63}$.

Crystal structures have been solved for recombinant forms of all three protein subunits of the S. pyogenes pilus $^{61,63,68}$. These provide the opportunity to derive an atomic model for assembled pili ${ }^{72}$ (FIG. 3a). Two questions about the structure of the pili of $S$. pyogenes and other Gram-positive bacteria remain to be answered. First, what is the role, if any, of post-translational modifications such as glycosylation of subunits? The presence of multiple $N$-glycosylation sites and the aberrant migration of Enterococcus faecium pilus components through SDS-PAGE suggests that such modifications may occur $^{73}$. However, as these modifications cannot occur within the recombinant subunits, biochemical and/ or mass spectrometry analysis of the entire pilus may uncover additional modifications in the pilins. Second, is the atomic model of the pilus based on crystal structures correct? Future high-resolution imaging of native pili should uncover the repeated head-to-tail organization of major and minor subunits in the assembled fibre.

Crystal structures of pilus subunits from other bacteria - including BcpA, the major pilin of B. cereus $^{74}$, SpaA, the major pilin of C. diphtheriae ${ }^{75}, \operatorname{RrgA}$, the tip adhesin of $S$. pneumoniae ${ }^{76}$, and Gbs52, the anchoring subunit of $S$. agalactiae ${ }^{61}$ - have been solved. Although the N-terminal Ig-like domain of BcpA $\left(\mathrm{Cna}_{1}\right)$ could not be crystallized, the structure of the remainder of the molecule showed that it comprises three domains designated $\mathrm{Cna}_{2}$ and $\mathrm{Cna}_{3}$, for their Ig-like $\mathrm{Cna}$-B structures, and Xna, which contains a jelly-roll fold ${ }^{74}$. Within the assembled pilus, each of the four domains of BcpA harbours an intramolecular isopeptide bond derived from Lys and Asn (via a catalytic Glu in $\mathrm{Cna}_{1}, \mathrm{Cna}_{2}$ and $\mathrm{Cna}_{3}$ and via an Asp residue in $\mathrm{Xna}$ ), but the recombinant $\mathrm{BcpA}$ protein lacks the bond in the $\mathrm{Cna}_{1}$ domain; this bond is formed only after BcpA has been polymerized by $\mathrm{SrtD}^{74}$.

SpaA, the major pilin of $C$. diphtheriae, is composed of three tandem Ig-like domains in which the middle and C-terminal domains are stabilized by intramolecular Lys-Asn isopeptide bonds ${ }^{75}$. Surprisingly, the C-terminal Ig-like domain of recombinant SpaA is stabilized by an internal disulphide bond; disulphide isomerization as a source for disulphide bonds in secreted proteins has not been reported for other Gram-positive bacteria ${ }^{77}$.

The major pilin of S. pneumoniae, $\operatorname{RrgB}$, is composed of four domains, designated D1-D4. A crystal structure of residues 184-627, which includes D2-D4, showed that each of these domains assembles into a $\beta$-sandwich structure with an intramolecular isopeptide bond reminiscent of the Ig-like fold of other pilin proteins ${ }^{76}$. Fitting of the partial RrgB fragment crystal structure into the overall structure of assembled RrgB pili, as analyzed by 
Table 2 | The roles of Gram-positive pili

\begin{tabular}{|c|c|c|c|}
\hline Bacterium & Pilins & Pilus function & Refs \\
\hline Staphylococcus intermedius & Saf2 and Saf3 & - Adherence to salivary agglutinin & 124 \\
\hline Actinomyces naeslundii T14V & $\begin{array}{l}\text { FimP and FimQ (type 1), and } \\
\text { FimA and FimB (type 2) }\end{array}$ & $\begin{array}{l}\text { - Adherence to tooth enamel } \\
\text { - Formation of surface glycoconjugates }\end{array}$ & $10,125-128$ \\
\hline $\begin{array}{l}\text { Corynebacterium diphtheriae } \\
\text { NCTC13129 }\end{array}$ & $\begin{array}{l}\text { SpaA, SpaB, SpaC, SpaD, SpaE, SpaF, } \\
\text { SpaH, Spal and SpaJ }\end{array}$ & - Adherence to epithelial cells & 54 \\
\hline Enterococcus faecalis OG1RF & EbpA, EbpB and EbpC & $\begin{array}{l}\text { - Adherence during biofilm formation } \\
\text { - Adherence during urinary tract infection }\end{array}$ & $85,91,104$ \\
\hline Lactobacillus rhamnosus GG & $\begin{array}{l}\text { SpaA, SpaB, SpaC, SpaD, SpaE and } \\
\text { SpaF }\end{array}$ & -Adherence to human intestinal mucus & 129,130 \\
\hline $\begin{array}{l}\text { Streptococcus agalactiae } \\
\text { 2603V/R or COH1 }\end{array}$ & $\begin{array}{l}\text { Gbs } 80, \text { Gbs52 and Gbs104 (encoded } \\
\text { by PI-1) }\end{array}$ & $\begin{array}{l}\text { - Adherence to respiratory and intestinal epithelial cells } \\
\text { - Adherence during biofilm formation }\end{array}$ & 60,101 \\
\hline $\begin{array}{l}\text { Streptococcus agalactiae } \\
\text { NCTC10/84 }\end{array}$ & PilA, PilB and PilC & $\begin{array}{l}\text { - Adherence to and invasion of epithelial cells, resistance to } \\
\text { phagocytosis, and increased virulence in a mouse model } \\
\text { - Mutants lacking PilA are defective in adherence to host cells } \\
\text { - Mutants lacking PilB are defective in invasion of host cells, } \\
\text { less virulent in mice, and more susceptible to killing by } \\
\text { macrophages and neutrophils } \\
\text { - PilB protects against the antimicrobial peptide cathelicidin }\end{array}$ & 98,100 \\
\hline $\begin{array}{l}\text { Streptococcus gallolyticus } \\
\text { subsp. gallolyticus }\end{array}$ & Sbs7 and Acb & - Adherence to collagens type I, IV and V & 106 \\
\hline $\begin{array}{l}\text { Streptococcus pneumoniae } \\
\text { TIGR4 }\end{array}$ & $\begin{array}{l}\operatorname{RrgA} \text { and } \operatorname{RrgB} \text { (encoded by rlrA, also } \\
\text { known as PI-1) }\end{array}$ & $\begin{array}{l}\text { - Adherence to respiratory epithelial cells, modulation of } \\
\text { inflammatory responses and virulence in mice } \\
\text { - The tip adhesin binds fibronectin, collagen I and laminin I }\end{array}$ & $29,87,96$ \\
\hline $\begin{array}{l}\text { Streptococcus pyogenes M49 } \\
\text { or Alab49 }\end{array}$ & $\begin{array}{l}\text { BP, Cpa and FctB (all encoded in the } \\
\text { FCT3 region) }\end{array}$ & $\begin{array}{l}\text { - Virulence in a skin infection model } \\
\text { - Adherence to and bacterial internalization of Hep2 cells }\end{array}$ & $108,133,134$ \\
\hline
\end{tabular}

transmission electron microscopy, suggests that the pilin subunits are stacked head to tail during sortase-mediated assembly $^{76}$.

The structure of the recombinant RrgA adhesin of pneumococcal pili also consists of four domains (D1$\mathrm{D} 4)^{78}$. The C-terminal D4 domain is stacked against the D1 and D2 domains, each of which assumes an Ig-variant all- $\beta$ fold. These three domains are likely to function as a stalk for the presentation of the D3 domain at the tip of the assembled pilus. The folded structure of the large D3 domain, residues 219-586, resembles that of the A3 domain of human von Willebrand factor, a molecule known to mediate association between platelets and collagen during haemostasis (the formation of a blood clot $)^{79-81}$. As is the case in the Cpa adhesin of S. pyogenes, but not in the major pilins and ancillary pilins that are involved in anchoring pilus fibres in the bacterial envelope, the residues forming the tertiary structure of the RrgA D1 and D2 domains are interspersed throughout the primary amino acid sequence of the protein ${ }^{78}$. Thus, the structure does not follow a design plan laid down as a sequence of independent folding events in the primary structure of the protein. Two intramolecular isopeptide bonds stabilize the folded structure of recombinant RrgA. The D2 domain (residues 133-220 and 587-722) is stabilized by a bond between Lys191 and Asn695, and the D4 domain (residues 731-859) is stabilized by a bond between Lys742 and Asn854.

\section{Isopeptide bonds within assembled pili}

Evidence suggests that pilin-specific sortases mediate the assembly of pili in Gram-positive bacteria through 


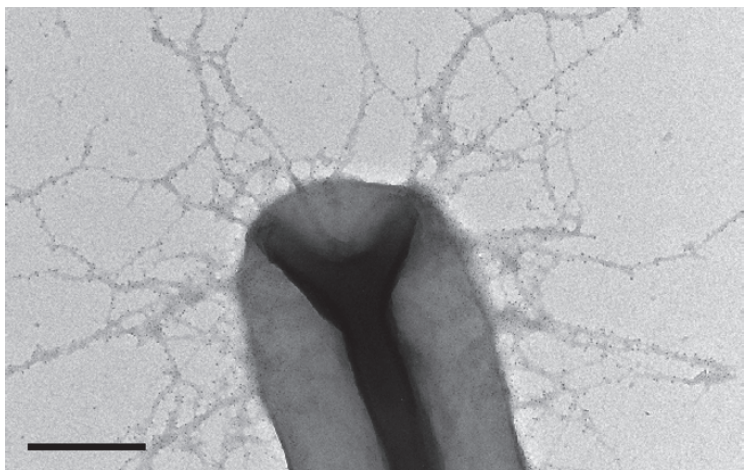

b

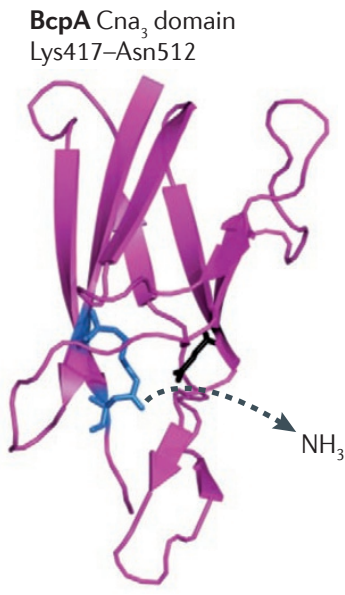

Spy0125 top domain Cys426-Gln575

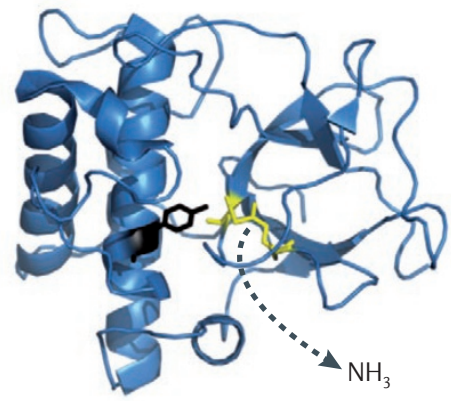

Cpa middle domain Lys297-Asp595

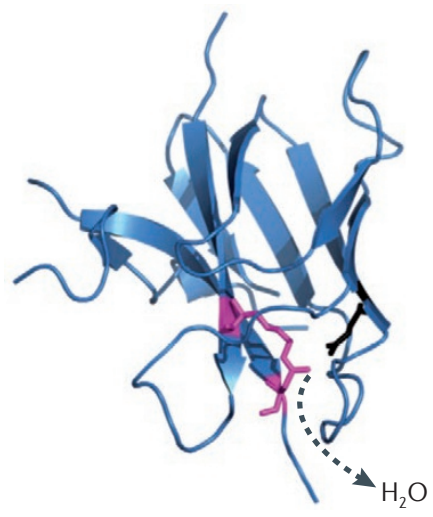

SpaA C-terminal domain Cys383-Cys443

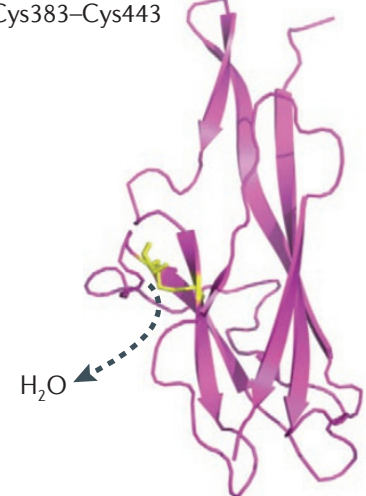

Figure 4 | Intramolecular isopeptide bonds assemble pili. a | Electron micrograph of protease resistant pili of Bacillus cereus in which the major subunit, BcpA, is labelled with $5 \mathrm{~nm}$ gold particles. The scale bar represents $200 \mathrm{~nm}$. b | Covalent intramolecular bonds discovered in pilin subunits. Autocatalytic generation of Lys-Asn and Lys-Asp isopeptide amide bonds in domains of pilin subunits eliminates an $\mathrm{NH}_{3}$ or $\mathrm{H}_{2} \mathrm{O}$ molecule, respectively. $X$-ray crystallography also showed the presence of intramolecular thioester and disulphide bonds, which are accompanied by the loss of an $\mathrm{NH}_{3} \mathrm{Or}_{2} \mathrm{O}$ molecule. Domains of major pilins are shown in magenta and those of minor subunits are shown in blue. (Part a electron micrograph courtesy of A.P.A.H.)

the formation of intermolecular isopeptide bonds. This hypothesis stimulated the bioinformatic approaches that not only identified major pilins with the YPKN pilin motif and the C-terminal sorting signal as putative pilus determinants, but also found gene clusters encompassing sortases ${ }^{82}$. These predictions were tested by examining bacterial surfaces for the presence of pili,

leading to the identification of pili on Actinomyces naeslundii $^{83,84}$, B. cereus $^{42}$, C. diphtheriae ${ }^{8}$, E. faecalis $^{85}$, E. faecium $^{86}$, S. agalactiae ${ }^{43}$, S. pneumoniae ${ }^{87}$ and S. pyogenes ${ }^{44}$. As additional evidence to support the pilin-specificsortase hypothesis, assembly of these pili requires the expression of a major pilin and a pilin-specific sortase $^{14,55,56,85,88-92}$.

Nevertheless, these findings do not constitute definitive proof that pili of Gram-positive bacteria, other than $B$. cereus and S. pyogenes, are assembled from intermolecular and intramolecular isopeptide bonds. Using novel in vivo technology, Budzik and colleagues ${ }^{53}$ showed that the C-terminal carboxyl group of Thr522 of BcpA is linked by SrtD via an intermolecular isopeptide bond to the $\varepsilon$-amino group of Lys162 in the YPKN pilin motif of the next BcpA subunit. Four intramolecular isopeptide bonds are also formed, one for each of the four folded domains of BcpA: Cna ${ }_{1}$ (a Lys37-Asn 163 bond), Cna (a Lys174-Asn265 bond), Xna (a Lys273Asn383 bond) and $\mathrm{Cna}_{3}$ (a Lys417-Asn512 bond) ${ }^{35,74}$ (FIG. 4). By contrast, recombinant BcpA cannot form the intramolecular isopeptide bond Lys37-Asn163, and its $\mathrm{Cna}_{1}$ domain is sensitive to proteases. Upon SrtDmediated assembly of the pilus, BcpA acquires protease resistance and the ability to form the $\mathrm{Cna}_{1}$ intramolecular isopeptide bond ${ }^{74}$. $\mathrm{BcpB}$, the tip protein of $\mathrm{BcpA}$ pili, is also linked to the $\varepsilon$-amino group of Lys 162 in the YPKN pilin motif of the neighbouring BcpA subunit. This process is catalysed by SrtD, which cleaves the IPNTG sorting signal of BcpB between Thr and $\mathrm{Gly}^{41}$. Interestingly, the LPVTG sorting signal of BcpA (but not the IPNTG of $\mathrm{BcpB}$ ) can be recognized and cleaved by two enzymes, SrtD (the pilin specific class C sortase) and SrtA (the housekeeping class A sortase). Depending on the availability of these enzymes and the resulting acyl intermediates, pili are either extended via the incorporation of BcpA or transferred to lipid II for incorporation into the cell wall envelope. Recognition of polypeptide substrates for cleavage by SrtA or SrtD requires only the $\mathrm{C}$-terminal sorting signal ${ }^{53}$. However, completion of the transpeptidation reaction by a pilinspecific class $C$ sortase requires larger segments of the major pilin protein and cannot be accomplished with the YPKN peptide alone. The autocatalytic assembly of three intramolecular isopeptide bonds in BcpA is likely to occur through a mechanism requiring catalytic Glu or Asp residues (Glu223 in Cna 2 , Glu472 in $\mathrm{Cna}_{3}$ and Asp312 in Xna). The assembly of the fourth intramolecular isopeptide bond remains an enigma. Autocatalysis of Lys37-Asn 163 in the Cna ${ }_{1}$ domain of recombinant BcpA does not occur. Formation of the intermolecular isopeptide bond immediately adjacent to Asn163 - between subunits in pili is accompanied by the stabilization of $\mathrm{Cna}_{1}$, and by the acquisition of the Lys37-Asn163 intramolecular isopeptide bond ${ }^{74}$.

Studies of C. diphtheriae and S. pneumoniae pili that are assembled from three different subunits revealed that the tip and major pilin subunits are cleaved by pilinspecific class $\mathrm{C}$ sortases and not by the housekeeping class A sortase, whereas the ancillary subunit that forms 
the base of the pilus is cleaved by the class A sortase $\mathrm{e}^{57,89,90}$. These findings explain why expression of an ancillary pilin gene is essential for the cell wall anchoring of some pili in Gram-positive bacteria.

\section{Outlook on the frontiers of pilus research}

The hypothesis that sortases mediate formation of the pilus enabled predictions that allowed the identification and characterization of pili in the envelope of Grampositive bacteria. The resulting discoveries closed much of the knowledge gap about pilus structure and function between Gram-negative and Gram-positive bacteria (BOX 1; TABLE 2). Recent advances have described the involvement of minor (ancillary) subunits that serve either as adhesins at the tip of pili or as anchoring units for completed fibres in the cell wall envelope, enabling the predictions of the sortase-pilus hypothesis to be further refined. When combined with detailed views on the structure of pilin subunits and the protective value of antibodies directed at specific elements of assembled pili, this field aims towards a rational appreciation of the molecular events underlying the pathogenesis of infections caused by Gram-positive bacteria, and the design of vaccines that seek to prevent them (BOX 2).
Pilus research has also generated unexpected results, such as the discovery of intramolecular isopeptide bonds, disulphide bonds and thioester bonds in pilin subunits $^{61,68,75}$. Future work in this area will seek to understand how these bonds are formed and what their specific contributions are to the biology of bacteria. Research into Gram-positive pili challenges chemists to synthesize organic compounds that may function as pilicides ${ }^{93}$. Following the discovery of the structural elements and construction principles for pili in Gram-negative bacteria, the field is now moving towards in vitro assembly reactions with purified subunits ${ }^{94,95}$. Scientists working on the pili of Gram-positive bacteria are confronted with a similar challenge: the in vitro reconstruction of pilus fibres with the proper intramolecular and intermolecular amide bonds. Much work remains to be carried out, although a recent report on in vitro fibre polymerization by a pilin-specific sortase from S. pneumoniae is an exciting advance ${ }^{14}$. Last, the dynamics of pilus assembly in Gram-positive bacteria, and the interaction of these pili with host cells, have not been fully imaged. Sophisticated light, fluorescence and high-resolution electron microscopy techniques should provide new insights into these fascinating structures that have so long been invisible to microbiologists.

\section{Box 2 | Deriving vaccines from pili}

The exciting advances in the past decade of research into the pili of Gram-positive bacteria have laid the foundation for exploring the vaccine potential of pili. Several Gram-positive bacteria that have pili and cause severe human disease warrant vaccine development: Streptococcus agalactiae (the cause of neonatal meningitis), Streptococcus pneumoniae (the cause of pneumonia, meningitis and otitis media) and Streptococcus pyogenes (the cause of pharyngitis, soft tissue infections and rheumatic fever) ${ }^{23}$. In addition, both Entercoccus faecalis and Entercoccus faecium (the causes of urinary tract infections, bacteraemia and endocarditis) have emerged as multidrug-resistant nosocomial pathogens, emphasizing the need for new antibiotics or vaccine development to prevent enterococcal infections ${ }^{22,110,111}$. Licensed vaccines against bacterial infections typically achieve antibody-mediated neutralization of key virulence traits associated with the pathogens, such as the inactivation of secreted toxins (tetanus or diphtheria vaccines) or the deposition of antibodies on capsular polysaccharides to overcome the anti-phagocytic attributes of these structures ${ }^{12,113}$. Examples of important diseases caused by sugar-coated microorganisms with capsular polysaccharides that have played a role in vaccine development are pneumococcal pneumonia ${ }^{114}$, meningococcal meningitis ${ }^{115}$, or neonatal meningitis that is caused by Haemophilus influenza $e^{116}$. Is it possible to derive vaccines against bacterial pili for specific human diseases in which pilus expression is a prerequisite for pathogenesis? This has certainly been attempted, with pilus subunit vaccines to protect women against piliated Escherichia coli urinary tract infection, for example ${ }^{117,118}$.

S. agalactiae tip pilins and major pilins have been used as subunit vaccines in mice. Maternal pilin-specific antibodies are transferred to the fetus and confer protection to newborn animals against lethal S. agalactiae challenge ${ }^{119}$. These streptococci produce pili from any one or two of the three pilus gene clusters (pilus islet 1 (PI-1), PI-2a and PI-2b). Although the PI-1 and PI-2b gene clusters are well conserved, the third $\mathrm{p}$ ' ine development currently focuses on the two major pilins of the conserved islands, $\mathrm{PI}-1$ and $\mathrm{PI}-2 \mathrm{~b}$, as well as the tip protein from PI-2a. Most S. agalactiae strains isolated from human neonatal meningitis cases express capsular polysaccharide, and antibodies against capsular material can confer protective immunity against neonatal meningitis. However, about $10 \%$ of S. agalactiae strains are non-encapsulated, and vaccine protection against this population could be addressed by developing pilus-specific vaccines.

One problem in the design of anti-pilin vaccines is the variability in the pilin subunits of a species. For example, all S. pyogenes strains examined produce pili from nine different chromosomal pathogenicity islands. These pili are assembled from three different pilin subunits: the major pilin, of which there are 15 variants; the tip pilin, of which there are 16 variants; and the ancillary pilin at the pilus base, of which there are five variants ${ }^{23,120}$. A vaccine derived from the 12 most frequently isolated variants of the major pilin may confer protection against about $90 \%$ of all clinical isolates ${ }^{120}$.

Two basic S. pneumoniae pilus types have been identified, each containing three pilin subunits. Pneumococcal isolates express neither, one or both of the corresponding pilus gene clusters on the bacterial surface ${ }^{121}$. Vaccine studies of the purified pilin subunits ( $\operatorname{RrgA}$, $\operatorname{RrgB}$ and $\operatorname{RrgC}$ ), of clinical serotype 4 strain S. pneumoniae TIGR4 indicated that any one pilus subunit can raise humoral immune responses with significant levels of vaccine protection ${ }^{122}$, although it is currently not clear whether pilus antigens offer an advantage over pneumococcal capsular polysaccharide vaccines that are already licensed by the US Food and Drugs Agency (FDA). 
1. Brinton, C. C. Jr. Non-flagellar appendages of bacteria. Nature 183, 782-786 (1959).

2. Houwink, A. L. Flagella, gas vacuoles and cell-wall structure in Halobacterium halobium; an electron microscope study. J. Gen. Microbiol. 15, 146-150 (1956).

3. Mudd, S., Polevitzky, K., Anderson, T. F. \& Chambers, L. A. Bacterial morphology as shown by the electron microscope: II. The bacterial cell-wall in the genus Bacillus. J. Bacteriol. 42, 251-264 (1941).

4. Swanson, J., Hsu, K. C. \& Gotschlich, E. C. Electron microscopic studies on streptococci. I. M antigen. J. Exp. Med. 130, 1063-1091 (1969).

5. Yanagawa, R., Otsuki, K. \& Tokui, T. Electron microscopy of fine structure of Corynebacterium renale with special reference to pili. Jpn. J. Vet. Res. 16, 31-37 (1968) The original report of pili in Corynebacterium spp.

6. Yanagawa, R. \& Honda, E. Presence of pili in species of human and animal parasites and pathogens of the genus Corynebacterium. Infect. Immun. 13 1293-1295 (1976).

7. Mazmanian, S. K., Liu, G., Ton-That, H. \& Schneewind, O. Staphylococcus aureus sortase, an enzyme that anchors surface proteins to the cell wall. Science $\mathbf{2 8 5}$ 760-763 (1999).

The discovery of sortase, the enzyme that covalently anchors surface proteins to the cell wall.

8. Ton-That, H. \& Schneewind, O. Assembly of pili on the surface of Corynebacterium diphtheriae. Mol. Microbiol. 50, 1429-1438 (2003).

The first demonstration that sortases and surface proteins assemble pili in a Gram-positive organism.

9. Schneewind, O., Fowler, A. \& Faull, K. F. Structure of the cell wall anchor of surface proteins in Staphylococcus aureus. Science 268, 103-106 (1995)

10. Ton-That, H., Liu, G., Mazmanian, S. K., Faull, K. F. \& Schneewind, O. Purification and characterization of sortase, the transpeptidase that cleaves surface proteins of Staphylococcus aureus at the LPXTG motif. Proc. Natl Acad. Sci. USA 96, 12424-12429 (1999).

11. Marraffini, L. A., Dedent, A. C. \& Schneewind, O. Sortases and the art of anchoring proteins to the envelopes of gram-positive bacteria. Microbiol. Mol. Biol. Rev. 70, 192-221 (2006).

12. Clancy, K. W., Melvin, J. A. \& McCafferty, D. G. Sortase transpeptidases: insights into mechanism, substrate specificity, and inhibition. Biopolymers 94, 385-396 (2010).

13. Ilangovan, U., Ton-That, H., Iwahara, J., Schneewind, O. \& Clubb, R. T. Structure of sortase, the transpeptidase that anchors proteins to the cell wall of Staphylococcus aureus. Proc. Natl Acad. Sci. USA 98 6056-6061 (2001).

14. Manzano, C. et al. Sortase-mediated pilus fiber biogenesis in Streptococcus pneumoniae. Structure 16, 1838-1848 (2008) The first report of in vitro pilus assembly using purified recombinant pneumococcal sortase and pilin subunits.

15. Neiers, F. et al. Two crystal structures of pneumococcal pilus sortase $\mathrm{C}$ provide novel insights into catalysis and substrate specificity. J. Mol. Biol. 393, 704-716 (2009).

16. Neiers, F. et al. Cloning, expression, purification, crystallization and preliminary X-ray analysis of the pilus-associated sortase C from Streptococcus pneumoniae. Acta Crystallogr. Sect. F. Struct. Biol. Cryst. Commun. 65, 55-58 (2009).

17. Zong, Y., Mazmanian, S. K., Schneewind, O. \& Narayana, S. V. The structure of sortase B, a cysteine transpeptidase that tethers surface protein to the Staphylococcus aureus cell wall. Structure 12 105-112 (2004)

18. Zhang, R et al. Structures of sortase B from Staphylococcus aureus and Bacillus anthracis reveal catalytic amino acid triad in the active site. Structure 12, 1147-1156 (2004)

19. Race, P. R. et al. Crystal structure of Streptococcus pyogenes sortase $\mathrm{A}$ : implications for sortase mechanism. J. Biol. Chem. 284, 6924-6933 (2009).

20. Weiner, E. M., Robson, S., Marohn, M. \& Clubb, R. T. The Sortase A enzyme that attaches proteins to the cell wall of Bacillus anthracis contains an unusual active site architecture. J. Biol. Chem. 285. 23433-23443 (2010)

21. Suree, N. et al. The structure of the Staphylococcus aureus sortase-substrate complex reveals how the universally conserved LPXTG sorting signal is recognized. J. Biol. Chem. 284, 24465-24477 (2009).
22. Hendrickx, A. P., Willems, R. J., Bonten, M. J. \& van Schaik, W. LPXTG surface proteins of enterococci. Trends Microbiol. 17, 423-430 (2009).

23. Soriani, M. \& Telford, J. L. Relevance of pili in pathogenic streptococci pathogenesis and vaccine development. Future Microbiol. 5, 735-747 (2010).

24. Mandlik, A., Swierczynski, A., Das, A. \& Ton-That, H. Pili in Gram-positive bacteria: assembly, involvemen in colonization and biofilm development. Trends Microbiol. 16, 33-40 (2008).

25. Pallen, M. J., Lam, A. C., Antonio, M. \& Dunbar, K. An embarrassment of sortases - a richness of substrates? Trends Microbiol. 9, 97-102 (2001)

26. Comfort, D. \& Clubb, R. T. A comparative genome analysis identifies distinct sorting pathways in grampositive bacteria. Infect. Immun. 72, 2710-2722 (2004).

27. Dramsi, S., Trieu-Cuot, P. \& Bierne, H. Sorting sortases: a nomenclature proposal for the various sortases of Gram-positive bacteria. Res. Microbiol. 156, 289-297 (2005)

28. Perry, A. M., Ton-That, H., Mazmanian, S. K. \& Schneewind, O. Anchoring of surface proteins to the cell wall of Staphylococcus aureus. III. Lipid II is an in vivo peptidoglycan substrate for sortase-catalyzed surface protein anchoring. J. Biol. Chem. 277. 16241-16248 (2002)

29. Patti, J. M., Allen, B. L., McGavin, M. J. \& Hook, M MSCRAMM-mediated adherence of microorganisms to host tissues. Annu. Rev. Microbiol. 48, 585-617 (1994).

30. Speziale, P. et al. Structural and functional role of Staphylococcus aureus surface components recognizing adhesive matrix molecules of the host Future. Microbiol. 4, 1337-1352 (2009)

31. Bierne, H. et al. Sortase B, a new class of sortase in Listeria monocytogenes. J. Bacteriol. 186, 1972-1982 (2004).

32. Marraffini, L. A. $\&$ Schneewind, O. Anchor structure of staphylococcal surface proteins. V. Anchor structure of the sortase B substrate IsdC. J. Biol. Chem. 280, 16263-16271 (2005)

33. Maresso, A. W. \& Schneewind, O. Iron acquisition and transport in Staphylococcus aureus. Biometals 19 193-203 (2006)

34. Maresso, A. W., Chapa, T. J. \& Schneewind, O. Surface protein IsdC and Sortase B are required for heme-iron scavenging of Bacillus anthracis. J. Bacteriol. 188 8145-8152 (2006)

35. Budzik, J. M. et al. Amide bonds assemble pili on the surface of bacilli. Proc. Natl Acad. Sci. USA 105 10215-10220 (2008)

The demonstration that pili are made of intermolecular isopeptide (amide) bonds between the YPKN motif and the sorting signal of neighbouring pilin subunits.

36. Manzano, C., Izore, T., Job, V., Di Guilmi, A. M. \& Dessen, A. Sortase activity is controlled by a flexible lid in the pilus biogenesis mechanism of Gram-positive pathogens. Biochemistry 48, 10549-10557 (2009).

37 Marraffini, L A. \& Schneewind, O Targeting protein to the cell wall of sporulating Bacillus anthracis. $\mathrm{Mol}$. Microbiol. 62, 1402-1417 (2006).

38. Marraffini, L. A. \& Schneewind, O. Sortase C-mediated anchoring of Basl to the cell wall envelope of Bacillus anthracis J. Bacteriol 189, 6425-6436 (2007).

39 Ton-That, H. Faull, K. F \& Schneewind O Anchor structure of staphylococcal surface proteins. A branched peptide that links the carboxyl terminus of proteins to the cell wall. J. Biol. Chem. 272, 22285-22292 (1997).

40. Navarre W. W. Ton-That, H., Faull, K. F. \& Schneewind, O. Anchor structure of staphylococcal surface proteins. II. $\mathrm{COOH}$-terminal structure of muramidase and amidase-solubilized surface protein J. Biol. Chem. 273, 29135-29142 (1998).

41. Budzik, J. M., Oh, S.-Y. \& Schneewind, O. Sortase D forms the covalent bond that links BcpB to the tip of Bacillus cereus pili. J. Biol. Chem. 284, 12989-12997 (2009)

42. Budzik, J. M., Marraffini, L. A. \& Schneewind, O. Assembly of pili on the surface of Bacillus cereus vegetative cells. Mol. Microbiol. 66, 495-510 (2007).

43. Lauer, P. et al. Genome analysis reveals pili in Group B Streptococcus. Science 309, 105 (2005)

44. Mora, M. et al. Group A Streptococcus produce piluslike structures containing protective antigens and Lancefield T antigens. Proc. Natl Acad. Sci. USA 102 15641-15646 (2005)

45. Scheffers, D. J. \& Pinho, M. G. Bacterial cell wal synthesis: new insights from localization studies. Microbiol. Mol. Biol. Rev. 69, 585-607 (2005).
46 Strominger J. L. Penicillin-sensitive enzymatic reactions in bacterial cell wall synthesis. Harvey Lect. 64, 179-213 (1968)

47. Boneca, I. G., Huang, Z. H., Gage, D. A. \& Tomasz, A. Characterization of Staphylococcus aureus cell wall glycan strands, evidence for a new beta-N-acetylglucosaminidase activity. J. Biol. Chem 275, 9910-9918 (2000)

48. Dmitriev, B. A., Toukach, F. V., Holst, O., Rietschel, E. T. \& Ehlers, S. Tertiary structure of Staphylococcus aureus cell wall murein. J. Bacteriol. 186, 7141-7148 (2004).

49. Cole, R. M. \& Hahn, J. J. Cell wall replication in Streptococcus pyogenes. Science 135, 722-724 (1962).

50. Pooley, H. M. Turnover and spreading of old wall during surface growth of Bacillus subtilis. J. Bacteriol. 125, 1127-1138 (1976).

51. Ghuysen, J. M., Tipper, D. J. \& Strominger, J. L. Structure of the cell wall of Staphylococcus aureus, strain Copenhagen. IV. The teichoic acid-glycopeptide complex. Biochemistry 4, 474-485 (1965).

52. Kline, K. A. et al. Mechanism for sortase localization and the role of sortase localization in efficient pilus assembly in Enterococcus faecalis. J. Bacteriol. 191, 3237-3247 (2009).

53. Budzik, J. M., Oh, S.-Y. \& Schneewind, O. Cell wall anchor structure of BcpA pili in Bacillus anthracis. J. Biol. Chem. 283, 36676-36686 (2008).

54. Mandlik, A., Swierczynski, A., Das, A. \& Ton-That, H. Corynebacterium diphtheriae employs specific minor pilins to target human pharyngeal epithelial cells. Mol. Microbiol. 64, 111-124 (2007).

55. Ton-That, H., Marraffini, L. A. \& Schneewind, O. Sortases and pilin elements involved in pilus assembly of Corynebacterium diphtheriae. Mol. Microbiol. 53, 251-261 (2004)

56. Guttilla, I. K. et al. Acyl enzyme intermediates in sortase-catalyzed pilus morphogenesis in gram-positive bacteria. J. Bacteriol. 191, 5603-5612 (2009).

57. Mandlik, A., Das, A. \& Ton-That, H. The molecular switch that activates the cell wall anchoring step of pilus assembly in gram-positive bacteria. Proc. Natl Acad. Sci. USA 105, 14147-14152 (2008).

58. Swierczynski, A. \& Ton-That, H. Type III pilus of corynebacteria: Pilus length is determined by the leve of its major pilin subunit. J. Bacteriol. 188 6318-6325 (2006).

59. Swaminathan, A. et al. Housekeeping sortase facilitates the cell wall anchoring of pilus polymers in Corynebacterium diphtheriae. Mol. Microbiol. 66, 961-974 (2007)

60. Krishnan, V. et al. An IgG-like domain in the minor pilin GBS52 of Streptococcus agalactiae mediates lung epithelial cell adhesion. Structure 15, 893-903 (2007).

61. Kang, H. J., Coulibaly, F., Clow, F., Proft, T. \& Baker, E. N. Stabilizing isopeptide bonds revealed in Gram positive bacterial pilus structure. Science $\mathbf{3 1 8}$, 1625-1628 (2007)

The first description of an intramolecular isopeptide (amide) bond in a pilus protein from a Gram-positive bacterium.

62. Deivanayagam, C. C. et al. Novel fold and assembly of the repetitive B region of the Staphylococcus aureus collagen-binding surface protein. Structure 8, 67-78 (2000).

63. Linke, C. et al. Crystal structure of the minor pilin FctB reveals determinants of Group A streptococcal pilus anchoring. J. Biol. Chem. 285, 20381-20389 (2010).

64. Kang, H. J. \& Baker, E. N. Intramolecular isopeptide bonds give thermodynamic and proteolytic stability to the major pilin protein of Streptococcus pyogenes. J. Biol. Chem. 284, 20729-20737 (2009).

65. Alegre-Cebollada, J., Badilla, C. L. \& Fernandez, J. M Isopeptide bonds block the mechanical extension of pili in pathogenic Streptococcus pyogenes. J. Biol. Chem. 285, 11235-11242 (2010)

66. Smith, W. D. et al. Roles of minor pilin subunits Spy0125 and Spy0130 in the serotype M Streptococcus pyogenes strain SF370. J. Bacteriol. 192, 4651-4659 (2010).

67. Manetti, A. G. et al. Streptococcus pyogenes pili promote pharyngeal cell adhesion and biofilm formation. Mol. Microbiol. 64, 968-983 (2007)

68. Pointon, J. A. et al. A highly unusual thioester bond in a pilus adhesin is required for efficient host cell interaction. J. Biol. Chem. 285, 33858-33866 (2010)

69. Law, S. K. \& Dodds, A. W. The internal thioester and the covalent binding properties of the complement proteins C3 and C4. Protein Sci. 6, 263-274 (1997). 
70. Cherry, S. \& Silverman, N. Host-pathogen interaction in drosophila: new tricks from an old friend. Nature Immunol. 7, 911-917 (2006).

71. Linke, C., Young, P. G., Kang, H. J., Proft, T. \& Baker E. N. Purification, crystallization and preliminary crystallographic analysis of the minor pilin FctB from Streptococcus pyogenes. Acta Crystallogr. Sect. F. Struct. Biol. Cryst. Commun. 66, 177-179 (2010).

72. Kang, H. J. \& Baker, E. N. Intramolecular isopeptide bonds: protein crosslinks built for stress? Trends Biochem. Sci. 4 Nov 2010 (doi:10.1016/j. tibs.2010.09.007).

73. Hendrickx, A. P. et al. Differential PilA pilus assembly by a hospital-acquired and a community-derived Enterococcus faecium isolate. Microbiology 156 2649-2659 (2010)

74. Budzik, J. M. et al. Intramolecular amide bonds stabilize pili on the surface of bacilli. Proc. Natl Acad. Sci. USA 106, 19992-19997 (2009).

75. Kang, H. J., Paterson, N. G., Gaspar, A. H., Ton-That, $\mathrm{H}$ \& Baker, E. N. The Corynebacterium diphtheriae shaft pilin SpaA is built of tandem Ig-like modules with stabilizing isopeptide and disulfide bonds. Proc. Natl Acad. Sci. USA 106, 16967-16971 (2009)

The first description of an intramolecular disulfide bond in a pilus protein from a Gram-positive bacterium.

76. Sarvas, M., Harwood, C. R., Bron, S. \& van Dijl, J. M. Post-translocational folding of secretory proteins in Gram-positive bacteria. Biochim. Biophys. Acta 1694 311-327 (2004)

77. Spraggon, G. et al. Supramolecular organization of the repetitive backbone unit of the Streptococcus pneumoniae pilus. PLoS ONE 5, e10919 (2010).

78. Izore, T. et al. Structural basis of host cell recognition by the pilus adhesin from Streptococcus pneumoniae. Structure 18, 106-115 (2010)

79. Bienkowska, J., Cruz, M., Atiemo, A., Handin, R. \& Liddington, $\mathrm{R}$. The von willebrand factor A3 domain does not contain a metal ion-dependent adhesion site motif. J. Biol. Chem. 272, 25162-25167 (1997)

80. Cruz, M. A., Yuan, H., Lee, J. R., Wise, R. J. \& Handin R. I. Interaction of the von Willebrand factor (vWF) with collagen. Localization of the primary collagenbinding site by analysis of recombinant vWF a domain polypeptides. J. Biol. Chem. 270, 10822-10827 (1995).

81. Springer, T. A. Complement and the multifaceted functions of VWA and integrin I domains. Structure 14 1611-1616 (2006)

82. Ton-That, H. \& Schneewind, O. Assembly of pili in Gram-positive bacteria. Trends Microbiol. 12 228-234 (2004)

83. Yeung, M. K., Chassy, B. M. \& Cisar, J. O. Cloning and expression of a type 1 fimbrial subunit of Actinomyces viscosus T14V. J. Bacteriol. 169, 1678-1683 (1987).

84. Yeung, M. K. \& Cisar, J. O. Cloning and nucleotide sequence of a gene for Actinomyces naes/undii WVU45 type 2 fimbriae. J. Bacteriol. 170, 3803-3809 (1988)

85 Nallapareddy, S. R. et al. Endocarditis and biofilmassociated pili of Enterococcus faecalis. J. Clin. Invest 116, 2799-2807 (2006)

86. Hendrickx, A. P. et al. Expression of two distinct types of pili by a hospital-acquired Enterococcus faecium isolate. Microbiology 154, 3212-3223 (2008).

87. Barocchi, M. A. et al. A pneumococcal pilus influences virulence and host inflammatory responses. Proc. Nat Acad. Sci. USA 103, 2857-2862 (2006).

88. Dramsi, S. et al. Assembly and role of pili in group B streptococci. Mol. Microbiol. 60, 1401-1413 (2006).

89. El, M. L., Terrasse, R., Dessen, A., Vernet, T. \& Di Guilmi, A. M. Stability and assembly of pilus subunits of Streptococcus pneumoniae. J. Biol. Chem. 285 , 12405-12415 (2010).

90. Falker, S. et al. Sortase-mediated assembly and surface topology of adhesive pneumococcal pili. Mol. Microbiol. 70, 595-607 (2008)

91. Kemp, K. D., Singh, K. V., Nallapareddy, S. R. \& Murray, B. E. Relative contributions of Enterococcus faecalis OG1RF sortase-encoding genes, srtA and $b p s$ (srtC), to biofilm formation and a murine model of urinary tract infection. Infect. Immun. 75, 5399-5404 (2007).

92. Lemieux, J., Woody, S. \& Camilli, A. Roles of the sortases of Streptococcus pneumoniae in assembly of the RIrA pilus. J. Bacteriol. 190, 6002-6013 (2008)

93. Hedenstrom, M. et al. NMR studies of interactions between periplasmic chaperones from uropathogenic E. coli and pilicides that interfere with chaperone function and pilus assembly. Org. Biomol. Chem. 3, 4193-4200 (2005).
94. Remaut, H. et al. Fiber formation across the bacterial outer membrane by the chaperone/usher pathway. Cell 133, 640-652 (2008)

95. Nishiyama, M. \& Glockshuber, R. The outer membrane usher guarantees the formation of functional pili by selectively catalyzing donor-strand exchange between subunits that are adjacent in the mature pilus. J. Mol. Biol. 396, 1-8 (2010).

96. Nelson, A. L. et al. RrgA is a pilus-associated adhesin in Streptococcus pneumoniae. Mol. Microbiol. 66 329-340 (2007).

97. Abbot, E. L. et al. Pili mediate specific adhesion of Streptococcus pyogenes to human tonsil and skin Cell. Microbiol. 9, 1822-1833 (2007).

98. Maisey, H. C., Hensler, M., Nizet, V. \& Doran, K. S. Group B streptococcal pilus proteins contribute to adherence to and invasion of brain microvascular endothelial cells. J. Bacteriol. 189, 1464-1467 (2007).

99. Konto-Ghiorghi, Y. et al. Dual role for pilus in adherence to epithelial cells and biofilm formation in Streptococcus agalactiae. PLoS Pathog. 5, e 1000422 (2009).

100. Maisey, H. C. et al. A group B streptococcal pilus protein promotes phagocyte resistance and systemic virulence. FASEB J. 22, 1715-1724 (2008).

101. Pezzicoli, A. et al. Pilus backbone contributes to group B Streptococcus paracellular translocation through epithelial cells. J. Infect. Dis. 198, 890-898 (2008)

102. Soriani, M. et al. Group B Streptococcus crosses human epithelial cells by a paracellular route. J. Infect. Dis. 193, 241-250 (2006)

103. Sillanpaa, J. et al. Characterization of the ebp pilusencoding operon of Enterococcus faecium and its role in biofilm formation and virulence in a murine model of urinary tract infection. Virulence 1, 236-246 (2010).

104. Singh, K. V., Nallapareddy, S. R. \& Murray, B. E. Importance of the $e b p$ (endocarditis- and biofilm associated pilus) locus in the pathogenesis of Enterococcus faecalis ascending urinary tract infection. J. Infect. Dis. 195, 1671-1677 (2007).

105. Hilleringmann, M. et al. Pneumococcal pili are composed of protofilaments exposing adhesive clusters of Rrg A. PLoS Pathog. 4, e 1000026 (2008)

106. Sillanpaa, J. et al. A collagen-binding adhesin, Acb, and ten other putative MSCRAMM and pilus family proteins of Streptococcus gallolyticus subsp. gallolyticus (Streptococcus bovis group, biotype I). J. Bacteriol. 191, 6643-6653 (2009).

107. Bessen, D. E. \& Kalia, A. Genomic localization of a T serotype locus to a recombinatorial zone encoding extracellular matrix-binding proteins in Streptococcus pyogenes. Infect. Immun. 70, 1159-1167 (2002).

108. Kreikemeyer, B. et al. Streptococcus pyogenes collagen type I-binding Cpa surface protein Expression profile, binding characteristics, biological functions, and potential clinical impact. J. Biol. Chem 280, 33228-33239 (2005).

109. Schneewind, O., Jones, K. F. \& Fischetti, V. A. Sequence and structural characteristics of the trypsinresistant T6 surface protein of group A streptococci. J. Bacteriol. 172, 3310-3317 (1990)

110. Murray, B. E. Vancomycin-resistant enterococcal infections. N. Engl. J. Med. 342, 710-721 (2000)

111. Werner, G. et al. Emergence and spread of vancomycin resistance among enterococci in Europe. Euro Surveill. 13, 19046 (2008)

112. Macleod, C. M., Hodges, R. G., Heidelberger, M. \& Bernhard, W. G. Prevention of pneumococcal pneumonia by immunization with specific capsular polysaccharides. J. Exp. Med. 82, 445-465 (1945)

113. von Behring, E. \& Kitasato, S. Über das zustandekommen der diphtherie-immunität und der tetanus-immunität bei Thieren. Dtsch. Med. Wochenschr. 16, 1113-1114 (1890) (in German).

114. Pletz, M. W., Maus, U., Krug, N., Welte, T. \& Lode, H. Pneumococcal vaccines: mechanism of action, impac on epidemiology and adaption of the species. Int. J. Antimicrob. Agents 32, 199-206 (2008).

115. Alonso, J. M. \& Taha, M. K. [Meningococcal vaccines: present status and perspectives]. Therapie 60 283-286 (2005) (in French).

116. Telford, J. L. Bacterial genome variability and its impact on vaccine design. Cell Host Microbe 3 , 408-416 (2008).

117. Serino, L., Moriel, D. G., Rappuoli, R. \& Pizza, M. Towards a vaccine against Escherichia coli-associated urinary tract infections. Future Microbiol. 5, 351-354 (2010)

118. Goluszko, P. et al. Vaccination with purified Dr Fimbriae reduces mortality associated with chronic urinary tract infection due to Escherichia coli bearing Dr adhesin. Infect. Immun. 73, 627-631 (2005).

119. Margarit, I. et al. Preventing bacterial infections with pilus-based vaccines: the group B streptococcus paradigm. J. Infect. Dis. 199, 108-115 (2009).

120. Falugi, F. et al. Sequence variation in group $A$ Streptococcus pili and association of pilus backbone types with lancefield T serotypes. J. Infect. Dis. 198 1834-1841 (2008)

121. Bagnoli, F. et al. A second pilus type in Streptococcus pneumoniae is prevalent in emerging serotypes and mediates adhesion to host cells. J. Bacteriol. 190 5480-5492 (2008)

122. Gianfaldoni, C. et al. Streptococcus pneumoniae pilus subunits protect mice against lethal challenge. Infect. Immun. 75, 1059-1062 (2007).

123. Yamaguchi, T., Matsumoto, M., Sugimoto, Y., Soutome, S. \& Oho, T. Gene cloning and characterization of Streptococcus intermedius fimbriae involved in saliva-mediated aggregation. Res. Microbiol. 160, 809-816 (2009).

124. Chen, P., Cisar, J. O., Hess, S., Ho, J. T. \& Leung, K. P. Amended description of the genes for synthesis of Actinomyces naeslundii T14V type 1 fimbriae and associated adhesin. Infect. Immun. 75, 4181-4185 (2007).

125. Clark, W. B., Wheeler, T. T. \& Cisar, J. O. Specific inhibition of adsorption of Actinomyces viscosus $\mathrm{T} 14 \mathrm{~V}$ to saliva-treated hydroxyapatite by antibody against type 1 fimbriae. Infect. Immun. 43, 497-501 (1984).

126. Gibbons, R. J. \& Hay, D. I. Human salivary acidic proline-rich proteins and statherin promote the attachment of Actinomyces viscosus LY7 to apatitic surfaces. Infect. Immun. 56, 439-445 (1988).

127. Gibbons, R. J., Hay, D. I., Cisar, J. O. \& Clark, W. B. Adsorbed salivary proline-rich protein 1 and statherin: receptors for type 1 fimbriae of Actinomyces viscosus T14V-J1 on apatitic surfaces. Infect. Immun. 56, 2990-2993 (1988)

128. Revis, G. J., Vatter, A. E., Crowle, A. J. \& Cisar, J. O. Antibodies against the Ag2 fimbriae of Actinomyces viscosus $\mathrm{T} 14 \mathrm{~V}$ inhibit lactose-sensitive bacteria adherence. Infect. Immun. 36, 1217-1222 (1982).

129. Kankainen, M. et al. Comparative genomic analysis of Lactobacillus rhamnosus GG reveals pili containing a human- mucus binding protein. Proc. Natl Acad. Sci. USA 106, 17193-17198 (2009).

130. von Ossowski, I. et al. Mucosal adhesion properties of the probiotic Lactobacillus rhamnosus GG SpaCBA and SpaFED pilin subunits. Appl. Environ. Microbiol. 76, 2049-2057 (2010)

131. Rinaudo, C. D. et al. Specific involvement of pilus type $2 \mathrm{a}$ in biofilm formation in group B Streptococcus. PLOS ONE 5, e9216 (2010).

132. Edwards, A. M. et al. Scavenger receptor gp340 aggregates group A streptococci by binding pili. $\mathrm{Mol}$. Microbiol. 68, 1378-1394 (2008)

133. Lizano, S., Luo, F. \& Bessen, D. E. Role of streptococcal T antigens in superficial skin infection. J. Bacteriol. 189, 1426-1434 (2007).

134. Nakata, M. et al. Mode of expression and functional characterization of FCT-3 pilus region-encoded proteins in Streptococcus pyogenes serotype M49. Infect. Immun. 77, 32-44 (2009).

\section{Acknowledgements}

We thank all the members of our laboratory for their contributions to sortase and pilin research and the excitement that accompanied our discoveries. Work on sortases and surface proteins was made possible by funding from the National Institute of Allergy and Infectious Diseases (NIAID), Infectious Diseases Branch, US National Institute of Health (NIH) (grants Al38897 and A169227). O.S. acknowledges membership of and support from the Region V 'Great Lakes' Regional Center of Excellence in Biodefense and Emerging Infectious Diseases Consortium (NIAID award 1-U54-AI-057153). J.M.B is trainee of the NIH Medical Scientist Training Program at The University of Chicago, Illinois, USA (GM07281).

Competing interests statement

The authors declare no competing financial interests.

FURTHER INFORMATION

Author's homepages: http://microbiology.uchicago.edu/ faculty-bios/olaf-schneewind.php

http://biomed.uchicago.edu/common/faculty/

schneewind.htm

ALL LINKS ARE ACTIVE IN THE ONLINE PDF 